\title{
Design Of Galvanic Cell Battery For Underwater Applications Using Seawater As Electrolyte
}

\author{
S.A.Thirumalini, D.Deepika, K.Muthumeenakshi, S.SakthivelMurugan
}

\begin{abstract}
Seawater battery is one of the green electricity sources to fulfill energy need for electrical equipment, especially in the coastal area and fishing activity.A survey was conducted among fishermen in which it was found that small scale fishermen uses lead acid battery and fuel cell in order to charge the mobile phone and glow the fishing lights. But major drawback of lead acid battery and fuel cell is that the maintenance cost is higher which is difficult for them to afford. Seawater is one most available sources all over the world and it is of no cost, hence a seawater battery is designed.Thispaper aims to study galvanic cells using sea water as electrolyte for energy harvesting. The electrochemical performances of Galvanic cells were carried out by measuring electric potentials by understanding the nature of conductivity of electrodes. The effect of sea water $\mathrm{pH}$ on electric potential was analyzed using sea water from different parts of Bay of Bengal with varying depths. Various combinations of electrodes like Graphite, Zinc, Copper, Aluminium, Brass and Iron were tested. A maximum yield of $1.1 \mathrm{~V}$ was obtained using the combination of Graphite-Iron as Cathode-Anode for a single cell. Further, we developed a working prototype for 16 cell. It generates a voltage of $12 \mathrm{~V}$ and $20 \mathrm{~mA}$. Since the output current obtained was not as desired so we added a current amplification circuit and obtained a maximum current of $300 \mathrm{~mA}$ from $20 \mathrm{~mA}$.
\end{abstract}

Keyword: Galvanic cell, seawater, Current amplification, electrolyte.

\section{INTRODUCTION}

Galvanic cell is an electrochemical device which directly converts chemical energy into electrical energy as long as electrolysis process exist. Galvanic cells have attracted much attention as an alternative energy source for portable electronic, electrical batteries. The secondary cell and fuel cell are mainly developed to avoid the disadvantages of generator. But, these fuel cell and secondary cell has various disadvantages like oil spill ,high cost of maintenance etc. In order to overcome these disadvantages, a galvanic cell battery is developed [1][2]

This project is to develop a stack arrangement of galvanic cell battery to provide the power, in order to charge the mobile phone and to glow the fishing light which are two major factor necessary for small scale fishermen day to day life.

Here the electrodes are selected and tested to find out which combination of electrode gives us good potential. Here sea water is used as electrolyte[3]. After the selection of electrode ,then it is tested to find which arrangement and connection help us to achieve good potential. Then it subjected under various condition. Since the current

Revised Manuscript Received on July 22, 2019.

S.A.Thirumalini, Final Year ECE, SSN College of Engineering

D.Deepika, Final Year ECE, SSN College of Engineering

Dr. K.Muthumeenakshi, Associate Professor, SSN College of Engineering,

Dr.S.SakthivelMurugan, Associate Professor, SSN College of Engineering produced by the battery is very less, current boosting circuit have been developed and validated in order to achieve the desired potential.

\section{II.METHODLOGY AND WORKING}

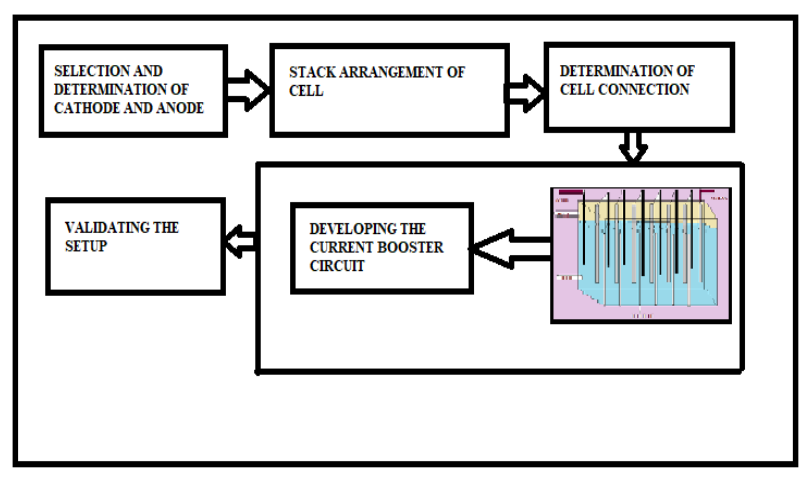

Fig 1: Design of Galvanic cell Battery

The Fig 1 shows the design of galvanic cell battery. At first the anode and cathode are selected which produces maximum potential. Then cells are arranged in stack as well provided with series connection Finally booster circuit are added in order to achieve the desired voltage

\section{Analyzing the Various Electrode}

The choice of electrode like copper, zinc, aluminum and graphite is analyzed using seawater as electrolyte[4].It has been tested with different sea water sample from different location like Pondicherry, Cuddalore, Mahabalipuram and Chennai which is collected at different depth like $5 \mathrm{~m}$, $10 \mathrm{~m}, 20 \mathrm{~m}$.It generate an voltage of about $1 \mathrm{~V}$.Electrode were tested in different combination and found that Graphite-Iron, Graphite-Zinc produces good potential. Fig 2 shows that the performance of electrode in sea water as electrolyte. Here, carbon is used as cathode and tested with variable anode. Finally it is concluded with Graphite-Iron combination. Moreover rusting Graphite take place when zinc is used as anode.

The Table II shows the quantitative analysis of cell. The obtained voltage from TABLE II is based on number of cells connected in series combination. From this it is understand that as number cell increases, voltage also increases.

TABLE III Performance

Analysis of various cell

under various condition

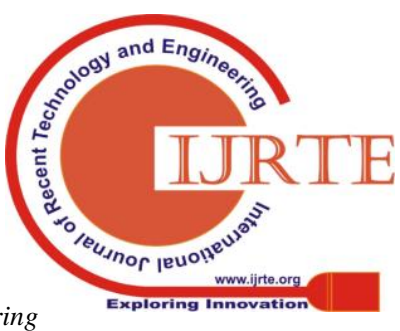
\& Sciences Publication 
DESIGN OF GALVANIC CELL BATTERY FOR UNDERWATER APPLICATIONS USING SEAWATER AS ELECTROLYTE

\begin{tabular}{|c|c|c|}
\hline $\begin{array}{c}\text { CONDITION } \\
\text { OF THE CELL }\end{array}$ & $\begin{array}{c}\text { TIME } \\
\text { PERIOD OF } \\
\text { (HOURS) }\end{array}$ & $\begin{array}{c}\text { VOLTAGE } \\
\text { OBSERVED } \\
(\mathrm{V})\end{array}$ \\
\hline $\begin{array}{l}\text { Without Zinc } \\
\text { metal }\end{array}$ & 23 & 12.03 \\
\hline $\begin{array}{l}\text { With Zinc } \\
\text { metal }\end{array}$ & 288 & 10.63 \\
\hline
\end{tabular}

Table III shows the performance of 16 cell battery with and without addition of poison material. It is found that using the Zinc as Poison material it withstand the potential of about 10 $\mathrm{V}$ for about 288 hours.

\section{Calculation of corrosion of iron}

The rate of corrosion is the speed at which any given metal deteriorates in a specific environment. The rate, or speed, is dependent upon environmental conditions as well as the type of the metal [13].

Corrosion rate is given by equation (5)

Corrosion Rate $=87.6 \times(\mathrm{W} /(\mathrm{DAT}))$

where,

$\mathrm{W}=$ Weight loss in milligram

$\mathrm{D}=$ Metal density in $\mathrm{g} / \mathrm{cm} 3$

$\mathrm{A}=$ Area of sample in $\mathrm{cm} 2$

$\mathrm{T}=$ Time of exposure of metal sample in hours

\section{CURRENT BOOSTER'S RESULTS}

As obtained current is insufficient it is necessary to amplify the current using current boosting circuits. This can be achieved using multisim software. The internal resistance calculated for the above battery is $600 \mathrm{Kilo}$ Ohm as shown in below Fig 3.3 The amp hour is calculated under idealistic condition .it is found that it has a capacity of $0.46 \mathrm{Ah}$. It is noted that battery will produce constant current of 20 milliampere for 23 hours.By using the above parameters, it is found that Current(A):20mA,Constant time: $23 \mathrm{hr}$

\section{Amp-Hr Calculation \\ Amp-Hr $(\mathrm{Ah})=\mathrm{Current}(\mathrm{A}) * \operatorname{Time}(\mathrm{Hr})$$$
=0.02 * 23
$$$$
=0.46 \mathrm{Ah} \text { or } 460 \mathrm{mAh}
$$

After calculation of amp hour and internal resistance, these values are incorporated to design an non ideal battery. Various circuits are simulated using non ideal battery.It is found the Fig 4 show s the current boosting which produces desired current and voltage

\section{Current Booster circuit using LM7812 and 1N4002}

This Fig 4 shows the current booster circuit using LM7812 and 1N4002. In general,LM7812 not only regulate the voltage,but also amplify the current.1N4002 amplify the current under forward bias condition.LM7812 regulator along with $1 \mathrm{~N} 4002$ diode amplify the current to about $1 \mathrm{~A}$. It produces an output voltage $12.54 \mathrm{~V}$ and $1.12 \mathrm{~A}$.

The output is validated in three phases

Validation of bottom module

Battery model is developed using acrylic material. The major advantage of using acrylic material container is that, it reduces water leakage when compared to other material containers. The prototype model of 16 cells is shown in the Fig 5 below

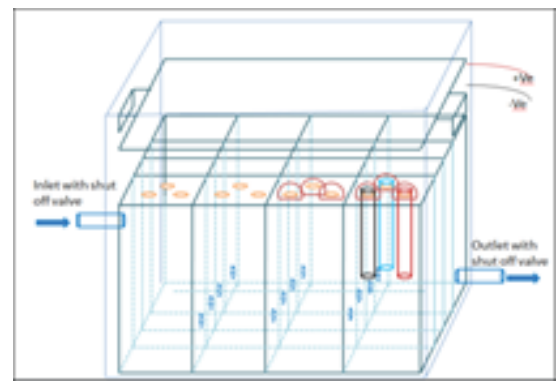

Fig 5: Prototype model of 16 CELLS

The Fig 5 shows the prototype model of 16 cell battery.

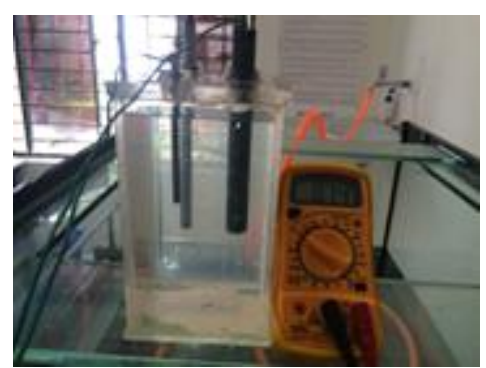

Fig 6: Customized single cell setup

The Fig 6 shows the Customized model of single cell battery. Further this setup has been extended to 16 cell as shown in Fig 7

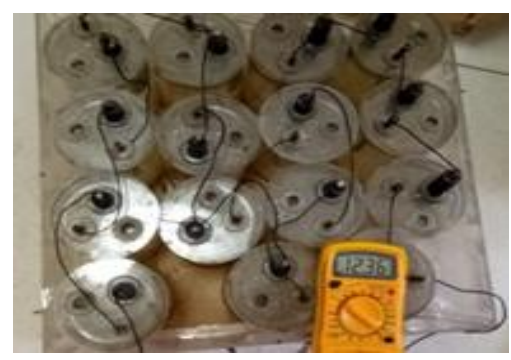

Fig 7: Customized single cell setup

Finally the setup have executed for 16 cell as shown in Fig 7.It produce an output voltage of $12 \mathrm{~V}$ and current of 20 milliampere

Validation of top module

Further the circuit are tested using a ordinary battery two 9

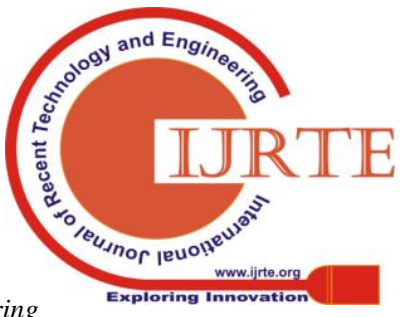
\& Sciences Publication 
V battery.Theinput current produced by this this battery is similar to that of battery that we developed and is approximately 20 milliampere

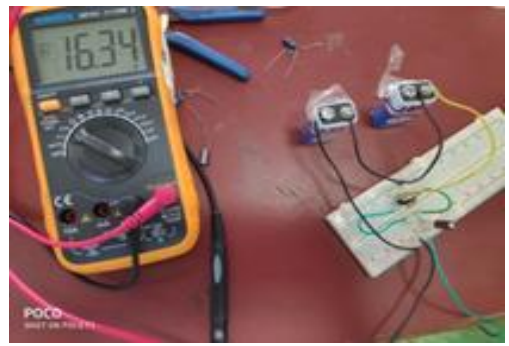

Fig 8: Circuit using LM7812 in an ordinary battery

The Fig 8 shows the circuit using ordinary battery LM7812 .It is found that the voltage obtained from the battery is 16.3 volt and current obtained from the battery is 18.2 milliamphere which is comparatively very less. Hence circuits need further improvement.

\section{Validation of top and bottom module}

The current booster circuit has been designed after making certain modification in the circuit like replacing $1 \mathrm{~N} 4002$ with 330 kilo ohm resistor and repacing the load with $10 \mathrm{ohm}$. the It is found that for 16 cell it produces an voltage of about $11.92 \mathrm{~V}$ and current of 300 milli ampere.

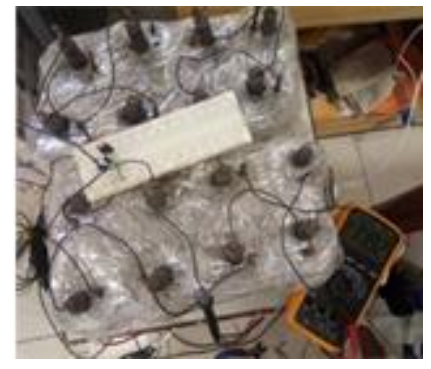

Fig 9: Modified Current booster Circuit incorporating top and bottom module

Fig 9 shows the voltage obtained after incorporating both top and bottom module. It is found that it produce an voltage of about $11.92 \mathrm{~V}$. The current obtained after incorporating both top and bottom module. It is found that it produce an voltage of about $12 \mathrm{v}$ and current of about 300 milliampere .Though, various modification are made in the current booster circuit, we can only achieve only 300 milliampere and at the same time voltage drops to $11.92 \mathrm{~V}$. Both the value are inefficient, since it cannot charge the mobile phone or glow the fishing lights. Therefore further improvement is needed for the circuit.

\section{IV.CONCLUSION}

This paper was started with motivation to provide a sufficient power mobile phone charger and to glow the fishing lights.The approximate voltage and current required is $12 \mathrm{~V}$ and 1A. With seawater as electrolyte,t is concluded that GRAPHITE-IRON combination produces good potential.
The customized battery of 16 cell produces voltage of $12 \mathrm{~V}$ and current of only 20 milliampere, which is very less. Therefore current boosting circuits is used to obtain higher value of current. After addition of current booster circuit, the battery produces the voltage of $12 \mathrm{~V}$ and current of about 300 milliampere.

rovide a first-rate living environment for people everywhere.

\section{REFERENCES}

1. Amir Vahid Dastjerdi and Rajkumar Buyya, "Fog Computing: Helping the Internet of Things Realize Its Potential", IEEE Communications Society, August 2016

2. Aref Meddeb, "Internet of Things Standards: Who Stands Out from the Crowd?", IEEE Communications Magazine - Communications Standards Supplement, July 2016.

3. Constantinos Kolias and Angelos Stavrou, Irena Bojanova, and Richard Kuhn, "Learning Internet of Things Security Hands-on", Copublished by the IEEE Computer and Reliability Societies, January/February 2016.

4. Dusit Niyato, Dinh Thai Hoang, Nguyen Cong Luong, Ping Wang, Dong In Kim, and Zhu Han, "Smart Data Pricing Models for the Internet of Things: A Bundling Strategy Approach", IEEE Network, March/April 2016.

5. David Park, "The Quest for the Quality of Things: Can the Internet of Things deliver a promise of the quality of things?", IEEE Consumer Electronics Magazine, April 2016.

6. Daqiang Zhang, Laurence Tianruo Yang, Min Chen, Shengjie Zhao, Minyi Guo, and Yin Zhang, "Real-Time Locating Systems Using the Active RFID for the Internet of Things", IEEE Systems Journal, Vol. 10, No. 3, September 2016.

7. David Metcalf, Sharlin T. J. Milliard, Melinda Gomez, and Michael Schwartz, "Wearables and the Internet of Things for Health", IEEE Pulse, September / October 2016.

8. Glenn Parsons, "The Internet of Things", IEEE Communications Magazine, July 2016.

9. Guiou Kobayashi, Maria Eunice Quilici-Gonzalez, Mariana Claudia Broens, and José Artur Quilici-Gonzalez, "The Ethical Impact of the Internet of Things in Social Relationships", IEEE Consumer Electronics Magazine, July 2016.

10. Huadong Ma, Liang Liu, Anfu Zhou, and Dong Zhao, "On the Networking of Internet of Things: Explorations and Challenges", IEEE Internet of Things Journal, Vol. 3, No. 4, August 2016.

11. Huadong Ma, Liang Liu, Anfu Zhou, and Dong Zhao, "On the Networking of Internet of Things: Explorations and Challenges", IEEE Internet of Things Journal, Vol. 3, No. 4, August 2016.

12. Jonathan Margulies, "Garage Door Openers: An Internet of Things Case Study", IEEE Computer and Reliability Societies, July/August 2015.

13. Keshav Sood, Shui Yu, and Yong Xiang, "Software-Defined Wireless Networking Opportunities and Challenges for Internet-of-Things: A Review”, IEEE Internet of Things Journal, Vol. 3, No. 4, August 2016.

14. Michele Nitti, Virginia Pilloni, Giuseppe Colistra, and Luigi Atzori, "The Virtual Object as a Major Element of the Internet of Things," IEEE Communications Surveys \& Tutorials, Vol. 18, No. 2, Second Quarter 2016.

15. Mohammad Abdur Razzaque, Marija Milojevic-Jevric, Andrei Palade, and Siobhán Clarke, "Middleware for Internet of Things: A Survey", IEEE Internet of Things Journal, Vol. 3, No. 1, February 2016.

16. Maria Rita Palattella, Mischa Dohler, and Alfredo Grieco, "Internet of Things in the 5G Era: Enablers, Architecture, and Business Models", IEEE Journal of Selected Areas in Communications, Vol. 34, No. 3, March 2016.

17. Mohamed Essaid Khanouche, Yacine Amirat, Abdelghani Chibani, Moussa Kerkar, and Ali Yachir, "Energy-Centered and QoS-Aware Services Selection for Internet of Things", IEEE Transactions on Automation Science and Engineering, Vol. 13, No. 3, July 2016.

18. Oladayo Bello and Sherali Zeadally, "Intelligent Device-to-Device Communication in the Internet of Things", IEEE Systems Journal, Vol. 10, No. 3, September 2016.

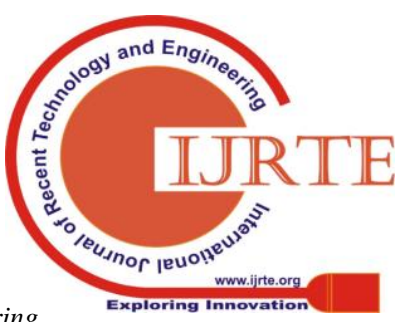

Eyes Intelligence Engineering \& Sciences Publication 
19. Phillip A. Laplante and Nancy Laplante, "The Internet of Things in Healthcare: Potential Applications and Challenges", IT Pro, IEEE Computer Society, May/June 2016.

20. Pawani Porambage, Mika Ylianttila, Corinna Schmitt, Pardeep Kumar, Andrei Gurtov, and Athanasios V. Vasilakos, "The Quest for Privacy in the Internet of Things", IEEE Cloud Computing, March/April 2016.

21. Phillip A. Laplante, Jefrey Voas, and Nancy Laplante, "Standards for the Internet of Things: A Case Study in Disaster Response", IEEE Computer Society, May 2016.

22. Sara Amendola, Rossella Lodato, Sabina Manzari, Cecilia Occhiuzzi, and Gaetano Marrocco, "RFID Technology for IoT-Based Personal Healthcare in Smart Spaces", IEEE Internet of Things Journal, Vol. 1, No. 2, April 2014.

23. Yi Xu and Abdelsalam Helal, "Scalable Cloud-Sensor Architecture for the Internet of Things", IEEE Internet of Things Journal, Vol. 3, No. 3, June 2016.

24. Yunchuan Sun, Houbing Song, Antonio J. Jara, and Rongfang Bie, "Internet of Things and Big Data Analytics for Smart and Connected Communities”, Digital Object Identifier 10.1109/Access, March 2016.

25. Yuvraj Agarwal and Anind K. Dey, "Toward Building a Safe, Secure, and Easy-to-Use Internet of Things Infrastructure", IEEE Computer Society, April 2016.

26. Zhangbing Zhou, Beibei Yao, Riliang Xing, Lei Shu, and Shengrong Bu, "E-CARP: An Energy-Efficient Routing Protocol for UWSNs in the Internet of Underwater Things", IEEE Sensors Journal, Vol. 16, No. 11, June 2016.

27. S.P. Raja, T. Dhiliphan Rajkumar and Vivek Pandiya Raj, Internet of Things: Challenges, Issues and Applications, Journal of Circuits, Systems and Computers, Vol. 27, No. 12, 2018.

28. S.P. Raja, T. Sampradeepraj, Internet of Things: a Research oriented Introductory, International Journal of $\mathrm{Ad} \mathrm{Hoc}$ and Ubiquitous Computing, Vol. 29, No. 1/2, 2018.

29. Rajesh, M., and J. M. Gnanasekar. "Path Observation Based Physical Routing Protocol for Wireless Ad Hoc Networks." Wireless Personal Communications 97.1 (2017): 1267-1289.

30. Rajesh, M., and J. M. Gnanasekar. "Sector Routing Protocol (SRP) in Ad-hoc Networks." Control Network and Complex Systems 5.7 (2015): 1-4.

31. Rajesh, M. "A Review on Excellence Analysis of Relationship Spur Advance in Wireless Ad Hoc Networks." International Journal of Pure and Applied Mathematics 118.9 (2018): 407-412.

32. Rajesh, M., et al. "SENSITIVE DATA SECURITY IN CLOUD COMPUTING AID OF DIFFERENT ENCRYPTION TECHNIQUES." Journal of Advanced Research in Dynamical and Control Systems 18.

33. Rajesh, M. "A signature based information security system for vitality proficient information accumulation in wireless sensor systems." International Journal of Pure and Applied Mathematics 118.9 (2018): 367-387.

34. Rajesh, M., K. Balasubramaniaswamy, and S. Aravindh. "MEBCK from Web using NLP Techniques." Computer Engineering and Intelligent Systems 6.8: 24-26. 